\title{
JAPAN MODERN: 60 JAAR JAPANSE PRENTEN IN HET RIJKSMUSEUM
}

Zestig jaar geleden vond in het Rijksmuseum de eerste tentoonstelling van Japanse prenten plaats. De aanleiding was de verwerving van 237 Japanse prenten uit de collectie van Ferdinand Lieftinck. De aankoop vormde het begin van de huidige collectie Japanse prenten van het Rijksmuseum die, in navolging van de collectie Lieftinck, vooral gericht was op de $17^{\mathrm{e}}$ tot en met de $19^{\mathrm{e}}$ eeuw.

En nu, 6o jaar na deze eerste tentoonstelling, is er wederom een goede reden voor een grote tentoonstelling van Japanse prenten. Dit keer kan moderne Japanse prentkunst uit de eerste helft van de $20^{\mathrm{e}}$ eeuw worden bewonderd. De aanleiding is nu wel een heel bijzondere, namelijk de aangekondigde schenking van Elise Wessels. Elise Wessels is directeur van Nihon no hanga, een privémuseum voor Japanse prentkunst in Amsterdam, en VVAK-lid. Haar collectie is gedurende de afgelopen 25 jaar bijeengebracht en bestaat momenteel uit circa 2000 Japanse prenten. Deze prenten, allemaal van uitmuntende kwaliteit, bieden een goed overzicht van de Japanse prentkunst uit de eerste helft van de $20^{\mathrm{e}}$ eeuw omdat ze de nieuwe prentstromingen van deze periode, shin hanga ('nieuwe prentkunst') en sōsaku hanga ('creatieve prentkunst'), weerspiegelen.

Het belangrijkste deel van deze bijzondere collectie komt op termijn naar het Rijksmuseum toe en zal een prachtige aanvulling vormen op de huidige verzameling prenten. Met de schenking van Elise Wessels zal ook de eerste helft van de $20^{\mathrm{e}}$ eeuw op zeer hoog niveau vertegenwoordigd zijn. Met recht een goede aanleiding voor een tentoonstelling!

\section{Shin hanga en sōsaku hanga}

Aan de hand van een selectie uit deze indrukwekkende collectie laat de tentoonstelling Japan Modern de bezoeker door de ogen van Japanse prentkunstenaars een kijkje nemen in de veel bewogen eerste drie decennia van de $20^{\mathrm{e}}$ eeuw.

Japan maakte een snelle modernisering door vanaf het einde van de $19^{\mathrm{e}}$ eeuw. De vele vernieuwingen en veranderingen als gevolg hiervan hadden grote invloed op verschillende aspecten van de Japanse samenleving. Nieuwe industrieën kregen volop kansen. Het landschap veranderde met de komst van grote fabrieken, nieuwe stalen bruggen en moderne hoogbouw (afb. I). Nieuwe sporten als zwemmen, skiën, golf, en teamsporten, vooral honkbal, wonnen snel terrein (afb. 2). Vrouwen in Japan ontplooiden zich net als Europese en Amerikaanse vrouwen meer en meer en werden in toenemende mate economisch onafhankelijik $k_{26 / 2023}$ 02:32:27pM 
Afb. 1

Koizumi Kishio,

De Eitaibashi en

Kiyosubashi bruggen, uitgegeven door

Asahi Press in 1928, kleurenhoutsnede, Japan, Collectie Nihon no Hanga,

Amsterdam, inv.nr. Poo28

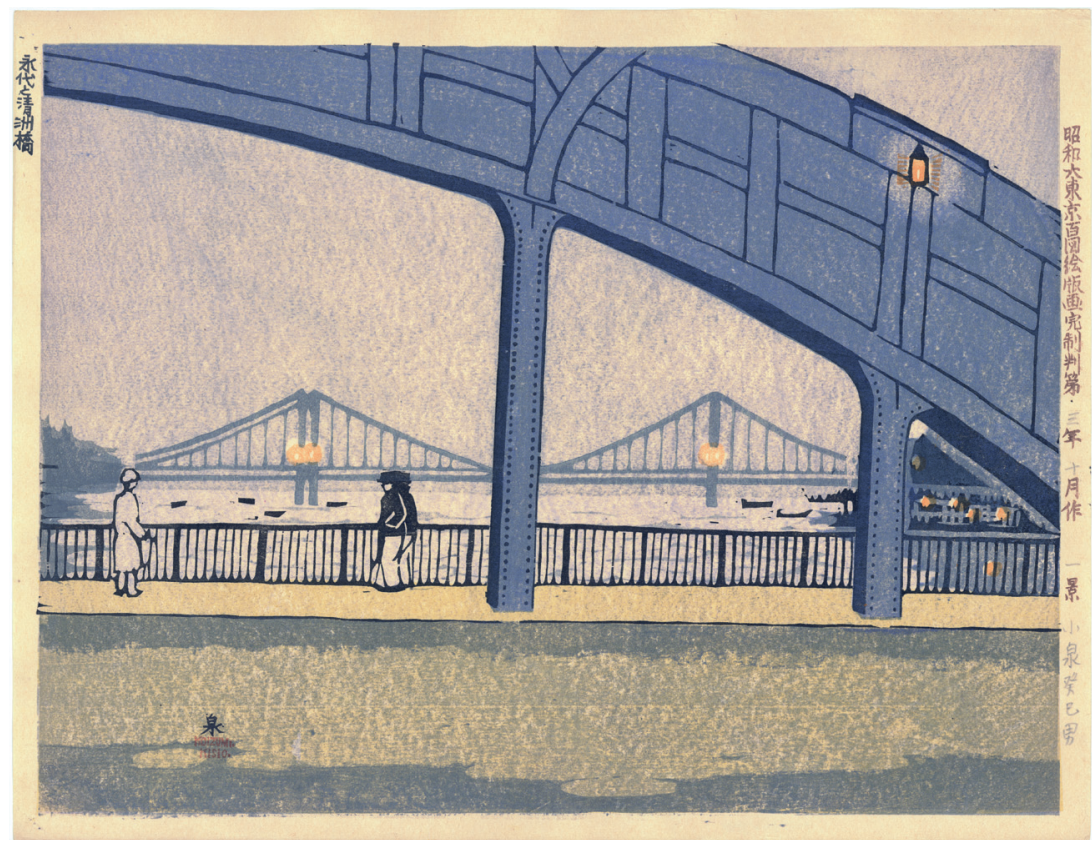

De vele mogelijkheden zorgden voor een nieuwe energie en in de steden heerste optimisme. Tegelijkertijd brachten de nieuwe mogelijkheden en veranderingen als gevolg van het snelle moderniseringsproces gevoelens van weemoed en onzekerheid met zich mee. Men twijfelde of Japan als onderdeel van de wijde wereld zijn eigen identiteit wel kon behouden. Dit zorgde voor een herwaardering van traditionele ambachten. Er ontstond een verlangen naar het oude Edo en de ongeschonden landschappen waar de moderne tijd niet aanwezig was.

Deze uiteenlopende gevoelens van optimisme tot weemoed en nostalgie bestonden naast elkaar en komen als geen ander tot uiting in de twee nieuwe prentstromingen die in deze periode ontstonden: de nieuwe prentkunst (shin hanga) en de creatieve prentkunst (sōsaku hanga). De kunstenaars van beide stromingen werkten met hetzelfde medium, de houtsnede, maar ze hadden elk heel eigen ideeën over de toepassing daarvan, over kunst en over het kunstenaarschap.

Shin hanga-kunstenaars werkten traditiegetrouw onder leiding van een uitgever en hun prentontwerpen werden door een gespecialiseerde bloksnijder en drukker tot een zeer verfijnd en gedetailleerd eindproduct omgezet. Deze prenten waren voor een groot deel gericht op een buitenlandse afzetmarkt. Het overgrote deel van de traditionele Japanse prentkunst, de ukiyo-e, had Japan tijdens het Japonisme in de tweede helft van de $19^{\mathrm{e}}$ eeuw verlaten. Hoewel de vraag naar prenten vanuit Europa over haar hoogtepunt heen was, groeide deze juist vanuit Amerika. Omdat het steeds moeilijker bleek om aan de toenemende vraag naar oude Japanse prentkunst te kunnen voldoen, werd naar nieuwe mogelijkheden gezocht. De uitgever Watanabe Shōzaburō zag mogelijkheden in de

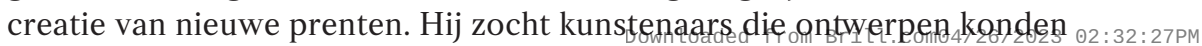


Afb. 2

Onchi Kōshirō,

Duiken, 1932,

kleurenhoutsnede,

Japan, Collectie

Nihon no Hanga,

Amsterdam,

inv.nr. Po560

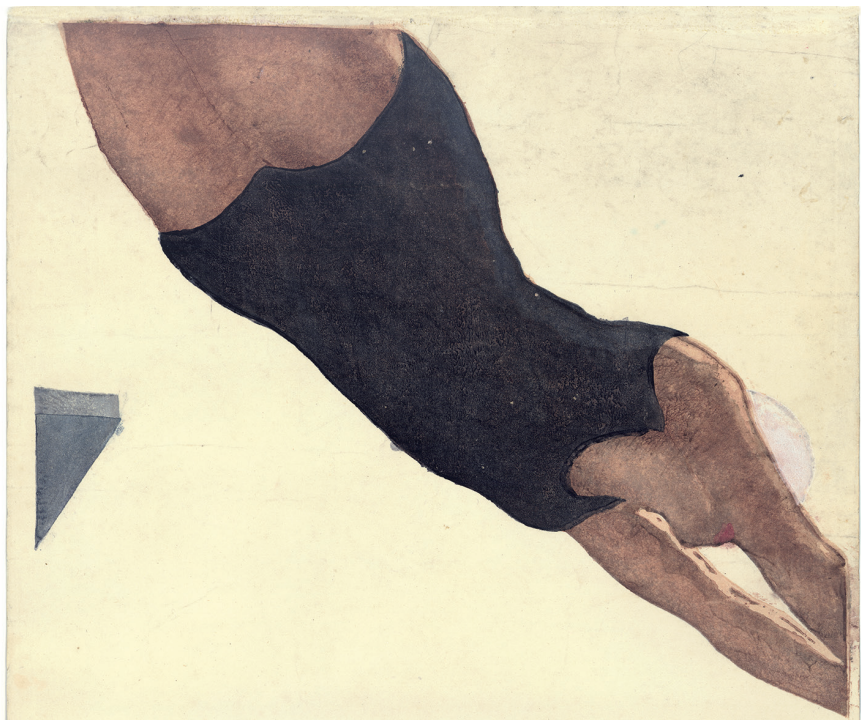


Afb. 3

Hashiguchi Goyō (1880-1921), Vrouw aan haar toilet, 1918, kleurenhoutsnede, Japan, Collectie Nihon no Hanga, Amsterdam, inv.nr. Po628

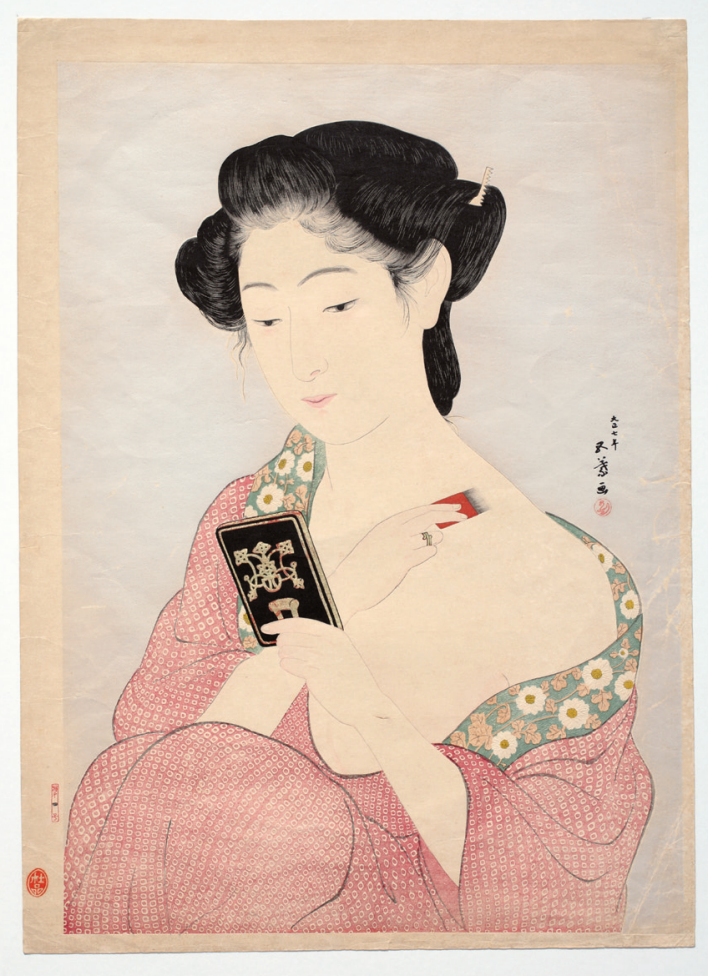

aanleveren, herinnerend aan de prentkunst uit de hoogtijdagen van de ukiyo-e. Dit waren vooral vrouwenportretten of landschapsprenten (afb. 3 en 4). Ze sloten aan bij de in Japan aanwezige nostalgische gevoelens en appelleerden aan de Amerikaanse smaak, doordat ze voldeden aan het grotendeels geromantiseerde Westerse beeld over een Japan van idyllische landschappen, tempels, badhuizen en courtisanes. Tegelijk blies Watanabe de eeuwenoude traditie van het prentmaken op deze manier nieuw leven in. Door het vervaardigen van de technisch zeer hoogstaande prenten, zorgde hij ervoor dat de ambachtelijke kennis van het bloksnijden en drukken niet verloren ging.

Sōsaku hanga-kunstenaars hadden daarentegen zeer vernieuwende ideeën over kunst en de rol van de kunstenaar. Kunstenaars dienden zelf verantwoordelijk te zijn voor het vervaardigen van hun prenten en het eindresultaat was vaak een prent met een opzettelijk grovere, meer onafgewerkte uitstraling. In het begin publiceerden sōsaku hangakunstenaars hun werk vooral in tijdschriften met kleine oplages. Ook de oplages van de prenten zelf waren vaak klein, soms werd zelfs maar één prent afgedrukt. Dit had enerzijds te maken met het ontbreken van een commercieel belang; het creatieve proces was vaak belangrijker dan de uiteindelijke prent. Anderzijds kwam het doordat de kunstenaar vaak het hele creatieproces zelf uitvoerde, waarnaast het snijden van het hout, maar ook het afdrukken, erg intensief werk was. En hoewel het in de beginjaren vooral draaide om het zelf ontwerpen, zelf snijden en zelf drukken, waren er al snel sōsaku hanga-kunstenaars die bepaalde onderdelen uitbesteedden aan gespecialiseerde houtspijders of drukkersers. 02:32:27pM 
Centraal bleef de overtuiging staan dat een kunstwerk de uiting van de creatieve geest van de kunstenaar diende te zijn; dat de kunstenaar zelf de creatie van een werk initieerde; zelf alle artistieke beslissingen nam en zeer nauw betrokken was wanneer hij onderdelen eventueel uitbesteedde.

Er was ook een duidelijk thematisch verschil bij beide stromingen.

Shin hanga-kunstenaars gaven vaak landschappen weer waar de moderne wereld afwezig leek te zijn. Sōsaku hanga-kunstenaars lieten echter juist vaak de actualiteit vanuit hun directe leefomgeving zien; de moderne stad en de nieuwe industrieën. Natuurlijk was het niet allemaal zo zwart-wit en

Afb. 4

Kawase Hasui,

De Yūhi waterval in

Shiobara, uit de serie

Reissouvenirs, de eerste

serie, uitgegeven

door Watanabe

Shōzaburō in 1920,

kleurenhoutsnede,

Japan, Collectie

Nihon no Hanga,

Amsterdam,

inv.nr. Po810

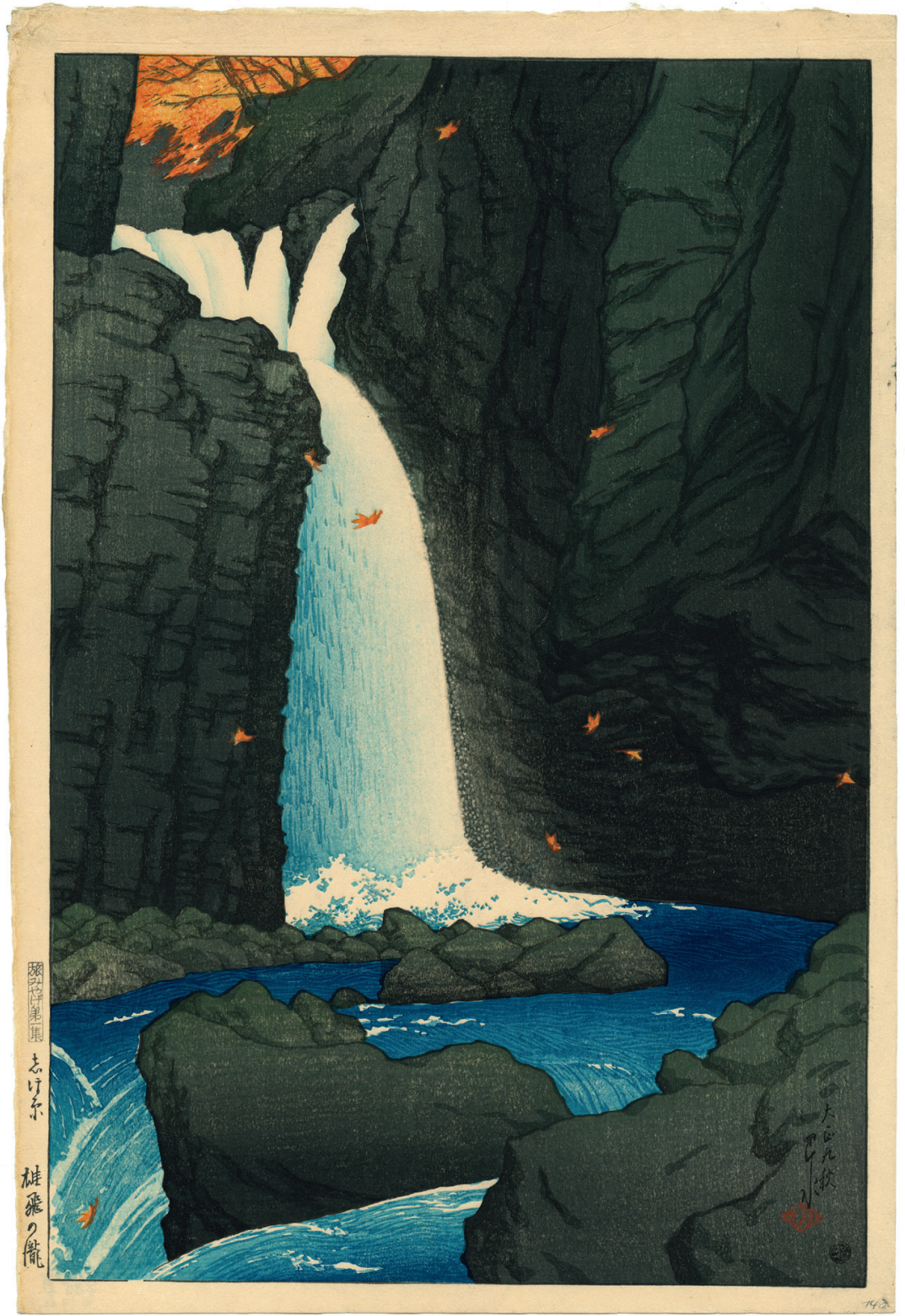


Afb. 5

Kobayakawa Kiyoshi, Danseres, uitgegeven door Hasegawa

Shoten in 1932 ,

kleurenhoutsnede, Japan, Collectie Nihon no Hanga, Amsterdam, inv.nr. Po140

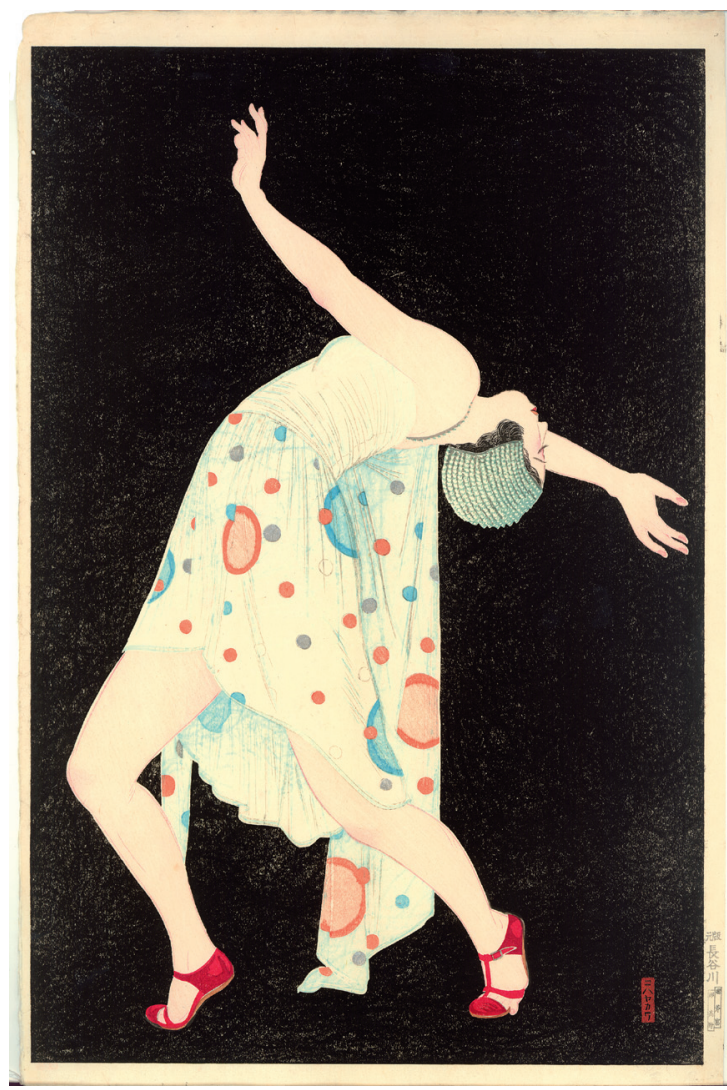

bestond er ook overlap in de thematiek. Voor beide stromingen vormde de Moga bijvoorbeeld een belangrijke inspiratiebron (afb. 5). Moga is een samenvoeging van modan gaaru (modern girl), 'modern meisje', vergelijkbaar met de Franse garçonnes, de Duitse neue Frauen, de modeng xiaojie in China en de Flappers in Amerika. De Moga droeg geen kimono, maar moderne kleding; een korte rok en hoge hakken. Ze was zelfstandig, werkte, rookte, dronk, droeg make-up, rode lippenstift en had een nieuw, kort (bob) kapsel. Ze sportte, ging uit en danste. Ze leek, kortom, in niets op de in kimono geklede traditionele Japanse huisvrouw. In de praktijk droegen de meeste Japanse vrouwen nog steeds een kimono, ${ }^{1}$ of combineerden traditioneel met modern, door het dragen van een kimono met een modern patroon of bijvoorbeeld een modern kapsel. Dit nieuwe vrouwbeeld, voor een groot deel door de filmindustrie gevisualiseerd, werd veelvuldig commercieel ingezet voor reclame-uitingen van de snel groeiende cosmetica-industrie, en werd daarna omarmd door schrijvers en kunstenaars. Voor shin hanga-kunstenaars was het nieuwe vrouwbeeld een moderne variant op de traditionele vrouwenportretten. Voor sōsaku hanga-kunstenaars stond de Moga symbool voor het moderne stadsleven.

\section{De moderne metropool Tokio}

Dit stadsleven werd op I september 1923 getroffen door een allesverwoestende aardbeving. Tokio werd volledig platgelegd, net als vele andere

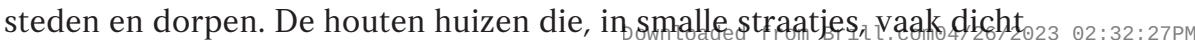


op elkaar stonden, werden volledig in de as gelegd door de enorme vuurzee die op de aardbeving volgde. Ondanks de desastreuze gevolgen van de aardbeving werd in Tokio al snel begonnen met de wederopbouw. Voor de aardbeving had het landschap in en rond de steden door de industrialisering al een gedaanteverwisseling ondergaan, maar de snelle wederopbouw na 1923 veranderde het landschap nog drastischer. De verwoeste houten laagbouw werd vervangen door moderne hoogbouw in meer vuurbestendige materialen als steen, beton en staal. Er werd een nieuwe infrastructuur aangelegd met verbrede wegen, moderne stalen bruggen en nieuwe vervoersmogelijkheden waaronder een uitgebreid metronetwerk. Het moderniseringsproces, dat al sinds het einde van de $\mathrm{I}^{\mathrm{e}}$ eeuw in Japan in gang was gezet, werd hierdoor versneld en uitgebreid.

Ook de mode-industrie nam een enorme vlucht met de komst van nieuwe materialen en productiemethodes. Synthetische stoffen en een nieuwe manier van het verven van katoen maakten het produceren van kimono's veel minder arbeidsintensief en minder kostbaar. De nieuwe grote warenhuizen verkochten confectiekimono's in vernieuwende motieven en kleuren aan een modebewust publiek.

In 1930 vierde Tokio het einde van de wederopbouw en stond er een nieuwe, moderne stad die in weinig opzichten nog leek op het Tokio van slechts enkele decennia eerder. Aan de hand van prenten uit beide stromingen worden de veranderingen en emoties als gevolg van de modernisering zichtbaar gemaakt.

- Marije Jansen is conservator Japanse prenten bij het Rijksmuseum en samensteller van de tentoonstelling Japan Modern. Collectie Elise Wessels. Marije studeerde Japanse taal en cultuur aan de Universiteit Leiden, waarna ze zich specialiseerde in de Japanse prentkunst. Daarnaast studeerde ze Kunstgeschiedenis aan de Universiteit van Amsterdam.

- De tentoonstelling Japan Modern. Collectie Elise Wessels is te zien vanaf vrijdag 24 juni t/m zondag II september 2016 in de Philipsvleugel van het Rijksmuseum. Bij de tentoonstelling verschijnt een catalogus in het Nederlands en het Engels. Tevens is er op zondag 26 juni een Rijkslezing door conservator Marije Jansen. Naast prenten uit de collectie Elise Wessels zijn er in de tentoonstelling ook contemporaine lakobjecten en kimono's uit de collectie van Jan Dees en René van der Star te zien, evenals affiches uit de collectie van het Museum of Modern Art, Tokyo.

\section{LITERATUUR}

Ewa Machotka, 'For girls and wives: narrating 'tradition' and 'modernity' through gendered publications of the Taishō era', Andon 97 (20I4), pp. 9I-IO4.

\section{NOOT}

I Onderzoek uit 1925 toont aan dat 99\% van de vrouwen in Ginza (een van de modernste wijken in Tokio) nog een kimono droeg. Zie Machotka 20I4: 97. 


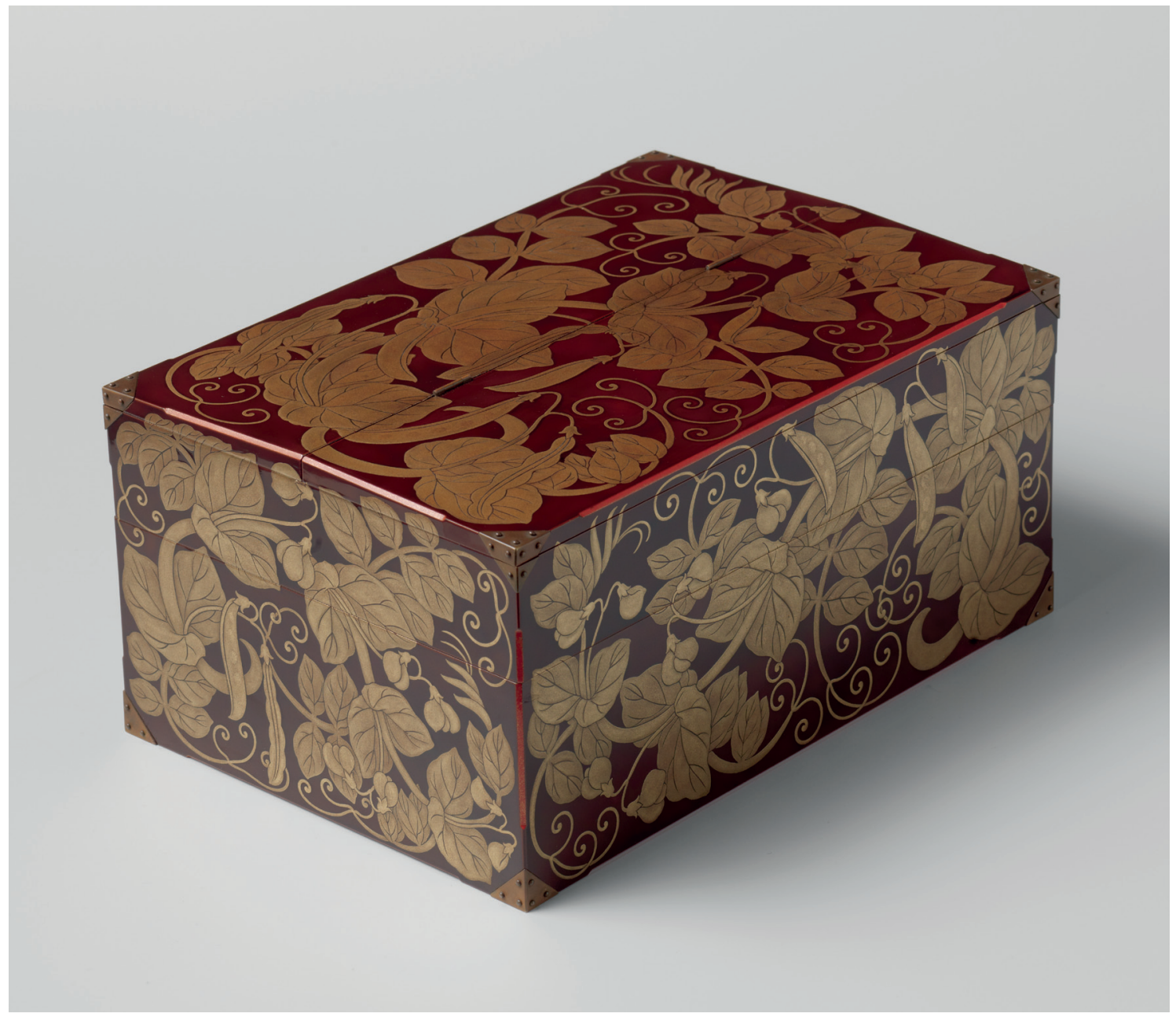

Afb. 1

De Erwtenplant schrijf\& papierdoos van Moriya Shōtei, 28,5 $\mathrm{x}$ 19,5 X 13,5 cm., Japan, 1930, Rijksmuseum Amsterdam, inv.nr. AK-C-2012-5, bruikleen van Jan Dees \& René van der Star 